The Research Journal of the Costume Culture

[Original Article]

Received March 29, 2017

Revised April 14, 2017

Accepted April 19, 2017

${ }^{\dagger}$ Corresponding author

(imjeann@hanmail.net)

ORCID

imsun Cho

http://orcid.org/0000-0002-3522-9863

Eunjin Lee

http://orcid.org/0000-0001-5372-8482

\section{Wedding culture \& lists of wedding gifts from the Gyungnam area in the 20th century}

\author{
Imsun Cho and Eunjin Lee
}

Dept. of Clothing \& Textile, Gyeongsang National University, Korea

\section{0세기 경남 지역의 혼례문화와 혼례물목}

\author{
조 임 선·이 은 진 ${ }^{\dagger}$ \\ 경상대학교 의류학과
}

\begin{abstract}
The study uses lists of wedding gifts used from old Korean documents written in Hangeul in the western Gyungnam province during the 20th century. The study analyzed four lists of wedding gifts from the Muncheongak archive and two lists from the archive of ancient document. This analysis found that clothing accounts for the majority of the items in the lists, and items such as furniture, jewelry, household goods, and medical materials were also recorded. That the furnishings were commonly prepared by the groom's side, and the fact that the number of jeogori was higher than the number of skirt, speaks to the unique wedding custom of Gyeongsang province. While the groom's list of wedding gifts included a record of the bride's ornaments, jewelry, and furnishings in the bride's list, the groom's nickel top-knot pin was only included as an ornament. In the list of wedding gifts between brothers, the gifts for the eldest son differed from those for the third son in terms of number and price. The list of wedding gifts between father and son illustrates how economic development and changing times wedding custom. The lists of wedding gifts in the old Korean documents shed light on the oral research into 20th century wedding custom, which will be used as basic data in researching and reproducting the wedding culture and life conditions of the time.
\end{abstract}

Keywords: list of wedding gifts(혼례물목), wedding ceremony of Gyeongnam area(경 남의 혼례), traditional wedding(전통혼례), Korea wedding culture in 20th century(20세기 한국 혼례문화)

\section{Introduction}

혼례물목은 혼례 때 사용되거나 주고 받은 모든 '물품 목록’을 의미한다(Kim, 2011). 혼례물목의 종류는 혼구물목(婚具物目), 납폐물목(納幣物目), 우귀물목(于歸 物目), 혼구·우귀물목, 부조록(扶助錄) 등이 있다. 혼구물목은 혼례 때 사용된 제반 품목과 수량, 가격, 사용처 등을 기록한 것이다(Kim, 2011). 납폐물목은 혼수물목, 물목단자라고도 불리며, 신랑측에서 신부측으로 보내는 예물이 많을 때 그 물목을 
별도로 적어 보낸 문건이다(Kim, 2011). 우귀물목은 신부가 초례를 마치고 신랑집으로 돌아올 때 신부측 에서 마련하는 살림살이와 예물 등을 기록한 것이다 (Kim, 2011). 혼구·우귀물목은 혼구물목과 우귀물목 이 한 문서에 기록된 형태이며, 부조록은 부조 물품 을 기록한 문건을 말한다(Kim, 2011).

혼례물목에 대한 선행 연구를 살펴보면, $\operatorname{Kim}(2011)$ 은 ‘혼례물목류(婚禮物目類) 고문헌 자료를 활용한 민 간 전통혼례 문화 연구'에서 혼례물목류의 양식적 특 성과 소장 실태를 고찰하였다. Kim(1982)은 “傳統婚 俗에서의 納徵禮에 대하여'에서 1932년대 혼례물목 1 정(定)과 년도미상 2 정의 고문서를 현대의 한글로 해 석하여 제시하였다. 경남 지방의 근대 혼례에 관한 선행연구를 살펴보면, Jeong(2000)은 '서부경남지방 의 전통혼례에 관한 민속학적 연구’라는 연구에서 1920년 1950년대를 중심으로 혼례사진과 면담, 전 화인터뷰를 병행하여 신랑과 신부복식, 혼례풍습을 고찰하였다. Hong, Lee, and Park(2002)은 '20세기 한 국의 혼례 문화 변천에 관한 연구'에서 서울과 경상 도 지역의 사례를 인터뷰 조사하여 경상도 지역의 혼 례풍습을 고찰하였다. 이처럼 경남 지역의 혼례에 대 한 선행연구들은 대부분 구술 연구에 의존한 혼례풍 습과 신랑-신부 차림에 관한 것이다. 또한 혼례물목 을 분석한 일부 연구의 경우에도 문서로서의 양식적 인 특성을 고찰한 것이다.

본 연구에서는 지역과 집안, 혼인연도, 혼인대상자 등의 정보가 정확한 경남 지역 혼례물목을 연구대상 으로 하여 20세기 경남 지역 혼례물목의 구성과 특성 을 분석함을 목적으로 하였다. 또한 기존 구술 연구 의 혼례풍습을 뒷받침하는 문헌적 근거 확보를 위해 본 연구가 필요할 것이다.

연구 방법은 첫째, 경상대학교 문천각 자료인 청주 한씨 집안(신랑 측)에서 작성한 혼례물목과 함안 이 씨 집안(신부 측)에서 작성한 혼례물목 2건, 둘째, 경 상대학교 문천각 자료인 고성 전주 최씨 집안의 최은 석과 최영덕의 부자간 혼례물목 2건, 셋째, 「고문서집 성 47권」에서 치부기록류로 수록된 단목 진양 하씨 집안의 형제간 혼례물목 2 건을 발췌하여 분석하였다. 마지막으로 고성 전주 최씨 집안을 방문하여 혼례물 목 자료에 대한 인터뷰를 하였다.

\section{Wedding Culture from the Gyungnam Area in the $20^{\text {th }}$ Century}

1972년에 발간된 「한국민속종합조사보고서 경상 남도편」의 구술자들은 인터뷰 당시의 나이가 70세 전 후로 1910년 1920년대에 결혼하였을 것으로 추정된 다. 이 구술자들의 인터뷰에 따르면 경남 지역의 혼 사는 남자 집안에서 당사자를 제외하고, 부모가 중심 이 되어 조부모, 삼촌, 형, 형수가 의견을 모았다. 우 선 여자집의 가문, 본가, 외가, 진외가까지 유전병 유 무와 가풍을 따졌다. 다음으로 결혼 상대 여자의 학 식, 덕성, 건강, 용모 등을 보았다. 중매인은 대체로 나이가 지긋하고 양가를 잘 아는 남자였으며, '중신 애비', ‘중매쟁이'라고 불렸다. 또 여자 중매인은 ‘중 신할미', ‘중신애미', ‘중매쟁이'라고 불렀으며, 때로 는 중매인이 남자가 아니라 여자인 경우에도 ‘중신애 비'라고 부르기도 하였다. 여자 측에서 혼사를 허락 하면 남자 측은 저고리 한 벌을 여자 집으로 보냈으 며, 이후 남자는 여자 집에 수시로 방문할 수 있었다 (Korean Culture and Information Service [KOCIS], 1972).

혼사가 성사된 후에는 신부의 치수를 신랑집으로 미리 통보하면 치수에 맞추어 옷감을 혼수함에 넣어 신부 집으로 보냈는데, 옷감의 양은 신랑 집안 형편 에 따라 달랐다(KOCIS, 1972). 또한 혼수함 안에는 혼서지, 신부의 장신구, 침선가[바느질삾]를 함께 넣 어 보내기도 하였다(KOCIS, 1972). 예단이 많을 경우 물품을 기록한 혼례물목을 혼수함에 넣었으며, 예단 물품들은 별도로 보냈다. 진주 단목 지역의 경우 노 랑저고리 - 빨강치마 한 벌만 혼수함에 넣어 혼례 전 날 신부집으로 보냈다(KOCIS, 1972).

경남 지역의 혼례풍습 중 혼수함은 서민의 경우, 첫 아들을 낳은 복 많은 사람이 지고 가며, 양반은 주 로 하인이 짊어지고 갔다(KOCIS, 1972). 함안 개평리 지역의 경우, 함진애비가 혼수함을 지고 신랑과 같이 동행하여 신부집으로 가기도 하였다. 독특한 예단 풍 습 중에는 돌아가신 시부모님께도 조상 예단의 명목 으로 당목으로 만든 치마-저고리, 버선을 준비하여 묘지 앞에서 태웠으며, 치마-저고리 수를 맞추지 않 고 대체적으로 치마보다 저고리를 하나 더 해주는 지 역적 풍습이 있다(Hong et al., 2002). 또한 혼수물품 
중 가구류인 장, 경대 등의 경우 다른 지역은 신부측 에서 마련하였으나, 경상도 지역은 신랑측이 마련하 는 지역적 특징이 있다(Hong et al., 2002).

1986년 발간된 「한국민속종합조사보고서 의생활 편」의 경상남도 지역 구술자들의 연령은 60 대 80 대 사이로 1910년 1940년 전후로 결혼했을 것으로 추 정된다. 당시 혼례풍습 중 남자의 바지 말기[허리]와 여자의 저고리 깃에 여름이라도 솜을 아주 얇게 넣었 는데, 이것은 힘든 결혼생활과 시집살이를 견뎌내고 잘 살라는 의미였다(KOCIS, 1986). 1915년 여성의 구술에 따르면 은가락지와 좋은 달비를 받으면 시집 을 잘갔다 여겼다고 한다. 옥, 백통 소재의 굵은 가락 지는 옷고름에 달아 장식적인 노리개 역할을 하여 ‘옷고름 가락지’라고 하였다(KOCIS, 1986). 1925년 에 결혼한 구술자에 의하면 낭자는 첫 아들을 출산한 복이 많은 동네 어른이 신랑이 신부집에 도착할 때에 맞춰 찌었다고 한다. 당시 낭자의 형태는 머리를 곱 게 빗어 땋지 않고 낭자를 하고 비녀를 꼽은 푼머리 낭자(쪽)와 두 가닥 혹은 세 가닥으로 땋아서 쪽을 찌 는 땋은 머리 낭자가 있었다. 머리숱이 많은 경우 세 가닥으로 땋아 낭자를 찌는데 어깨를 닿지 않았다고 한다(KOCIS, 1986)

혼례는 혼수함이 도착 다음 사시(已時: 오전 9시 오전 11시)사이에 치루었다(Jeong, 2000). 1940년 산 청의 혼례사진인 〈Fig. 1〉을 보면 신랑은 사모관대 차 림에 남바위를 착용하고, 신부는 청·홍색의 옷감으로 원삼을 흉내 내었으며, 향건, 족두리, 손찌를 착용하 였다(Jeong, 2000). 1949년 하동의 혼례사진인〈Fig. 2)에서도 신랑은 사모관대 차림에 남바위를 착용하고, 신부는 청색 옷감을 양어깨에서 앞뒤로 겹쳐 늘이고, 홍색 옷감을 허리에 묶었다. 머리에는 검은 천으로 족두리를 흥내냈으며, 양털로 만든 향건을 착용하였 다(Jeong, 2000). 향건은 옛날 면사(面紗)로 추정되고, 면사보다 크기가 작아진 것으로 수건 같이 생겼으며, 볼 옆으로 내려 착용하였다(KOCIS, 1986). 선행연구 에 따르면 1920년 50년대까지 진주, 거창, 산청, 하 동 등 여러 경남 지역에서 향건을 착용한 지역의 특 성이 나타나고 있다(Jeong, 2000). 경남 지역의 혼례 때 착용한 머릿보는 향건이 없을 때 족두리 밑에 착 용한 것으로 검은색 갑사 2폭으로 만들었다. 형태는 끈이 없고 $60 \mathrm{~cm}$ 정도의 크기로 보자기와 비슷하게

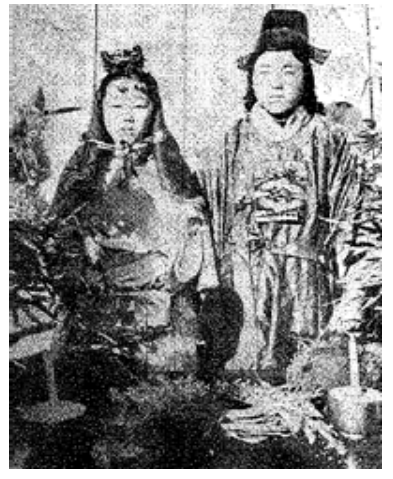

<Fig. 1> 1940's Gyeongnam Sancheong Town Traditional Wedding.

From. Jeong. (2000). p. 85 .

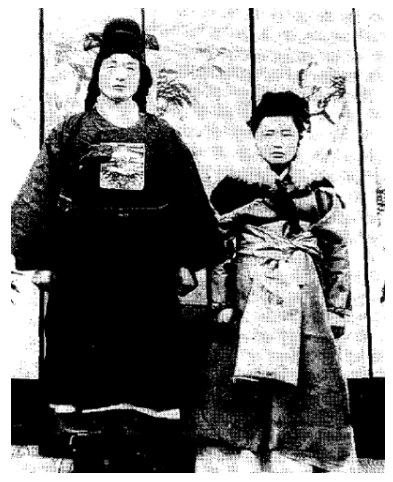

<Fig. 2> 1949's Gyeongnam Hadong Town Traditional Wedding. From. Jeong. (2000). p. 86.
만들어 머리 위에 둘러썼다. 정수리 부분에 머리 크 기 정도의 둥근 금박을 찍어 장식한 머리쓰개이다 (Jeong, 2000).

\section{Analysis of Lists of Wedding Gifts}

본 연구에서 고찰한 경남의 혼례물목은 〈Table 1〉 과 같이 6건이다. 6 건의 혼례물목에 기록된 품목은 의복류, 장신구류, 가구류, 생활용품류, 화장품류, 의 료소재류, 침선가로 구분할 수 있다. 6 건의 혼례물목 에서 품목의 기록 순서는 혼례물목에 따라 달랐다. 6 건의 혼례물목 중에 4 건은 가구류 $\rightarrow$ 장신구류 $\rightarrow$ 의 복류(상의 $\rightarrow$ 하의 $\rightarrow$ 옷감) $\rightarrow$ 의류소재류 $\rightarrow$ 화장품류 $\rightarrow$ 생활용품류 $\rightarrow$ 침선가의 순서로 기록되어 있다. 또, 1 건은 장신구류부터 기록되어 있으나, 가구류가 가장 뒤에 기록된 것만 차이가 있다. 나머지 1 건은 의복류 $\rightarrow$ 장신구류만 기록되어 있다.

각 혼례물목에는 일곱 가지 품목에 따른 종류와 수 량이 기록되어 있다. 그러나 품목별로 도량형의 단위 가 상이하여 수량으로 비중을 완전하게 비교하는 것 은 불가능하였다. 따라서 품목별 비중은 품목의 종류 를 기준으로 분석하였다.

\section{List of wedding gifts from the Hapcheon Cheong-} ju Han family \& Haman Lee family

〈Fig. 3〉과 〈Fig. 4〉의 혼례물목은 합천 가회에 살 던 청주 한씨 한범석의 아들 한경우(당시 12 세)와 산 
$<$ Table 1> List of wedding gifts

\begin{tabular}{c|c|c|c|c|c}
\hline No. & List of wedding gifts name & $\begin{array}{c}\text { Wedding } \\
\text { Year }\end{array}$ & Area & Item quantity & Reference \\
\hline 1 & Cheongju Han Family & 1915 & Hapcheon & 155 & Groom $\rightarrow$ Bride \\
\hline 2 & Haman Lee Family & 1915 & Sancheong & 95 & Bride $\rightarrow$ Groom \\
\hline 3 & Ha sunbong Family & 1918 & Jinju & 163 & Groom $\rightarrow$ Bride \\
\hline 4 & Ha sunbo Family & 1930 & Jinju & 140 & Groom $\rightarrow$ Bride \\
\hline 5 & Choi eeunseok Family & 1938 & Goseong & 163 & Groom $\rightarrow$ Bride \\
\hline 6 & Choi eyeongdeok Family & 1976 & Goseong & 29 & Groom $\rightarrow$ Bride \\
\hline
\end{tabular}

청 묵곡에 살던 함안 이씨 이상규(1846 1922년)의 딸 이필헌(李必憲, 당시 15세)이 1915년 혼례에 사용 한 혼례물목이다. 이처럼 양가에서 주고 받은 혼례물 목이 함께 남아 있는 경우는 매우 드물어 자료의 가 치가 높다(J. H. Lee, personal communication, September 11, 2015). 이 문서는 2010년 청주 한씨 병사 공파 문중에서 경상대학교 문천각에 기증 또는 영구 위탁한 고문서 1,000 여 점에 포함되어 있다(The Digital Library of Nammyong Study, 2011).

〈Fig. 3〉은 신랑측인 청주 한씨 집안에서 신부측인 함안 이씨 집안으로 보낸 혼례물목이다. 문서의 크기 가 약 $500 \mathrm{~cm} \times 26 \mathrm{~cm}$ 로 혼례물목의 종류와 수량이 많아 장정 30 40명이 짊어지고 갈 분량이었다고 한 다(The Digital Library of Nammyong Study, 2013). 혼례물목 위에 점이 있는 것은 수량을 확인한 흔적이 라고 사료된다.

〈Fig. 4〉는 함안 이씨 집안인 신부측에서 신랑측인 청주 한씨 집안으로 보낸 혼례물목이다. 문서의 크기 는 약 $248 \mathrm{~cm} \times 26 \mathrm{~cm}$ 이다.

〈Fig. 5〉는 청주 한씨 집안 혼례물목의 품목 종류 와 비중을 분석한 그래프이다. 청주 한씨 집안의 혼 례물목 품목 종류는 총 155 종이다. 이중 의복류가 98 종으로 전체 물목에 $63 \%$ 를 차지하며, 생활용품류가 22 종 $(14 \%)$, 장신구류가 17 종 $(11 \%)$, 가구류가 7종(5 $\%)$, 의료소재류가 7 종 $(5 \%)$, 화장품류가 4 종 $(2 \%)$ 이었 다.

〈Fig. 6〉은 함안 이씨 집안 혼례물목의 품목 종류 와 비중을 분석한 그래프이다. 함안 이씨 집안 혼례 물목의 품목 종류는 총 96 종이다. 이중 의복류가 75 종으로 전체 물목에 $78 \%$ 를 차지하며, 생활용품류가

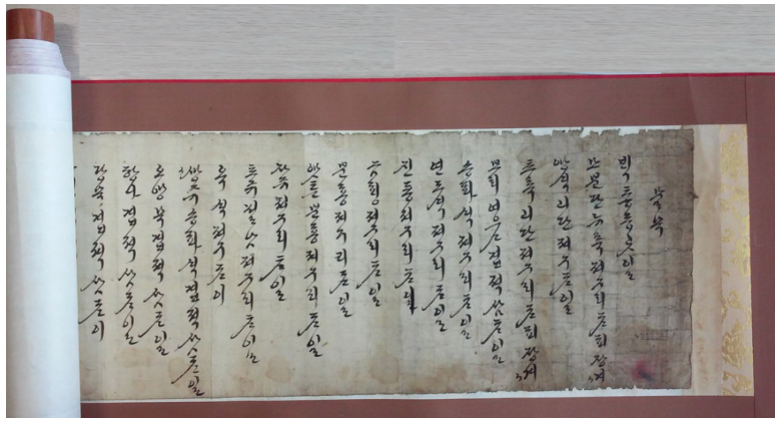

<Fig. 3> A list of wedding gifts from the Cheongju Han family. (Muncheongak at Gyeongsang National University)

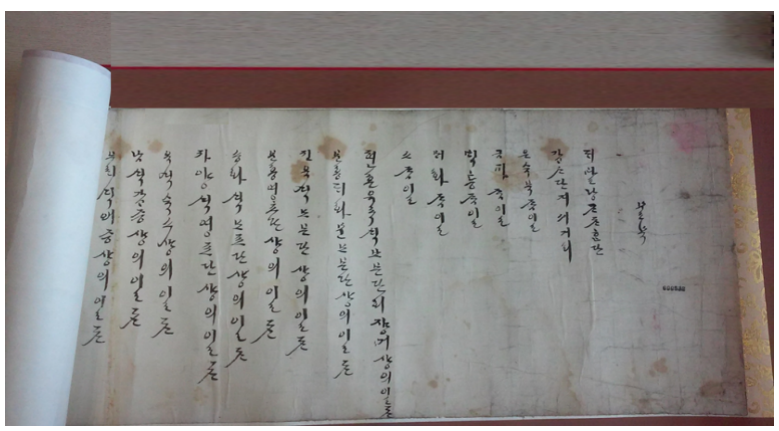

<Fig. 4> A list of wedding gifts from the Haman Lee family. (Muncheongak at Gyeongsang National University)

12 종(13\%), 의료소재류가 4종(4\%), 장신구류가 2종 $(2 \%)$, 화장품류가 2 종 $(2 \%)$, 침선가 1 건 $(1 \%)$ 이었다.

청주 한씨 집안 혼례물목의 품목 종류를 분석하면 〈Table 2〉와 같다. 의복류는 98종으로 겉옷은 저고리 27종 27점, 치마 24종 31점이다. 속옷은 적삼 9종 11 점, 바지 10 종 10 점, 단의 5 종 5 점, 단고의 3 종 3 점, 내의 2종 2점, 요대 1 종 1 점이다. 옷감은 17 종이 기록 


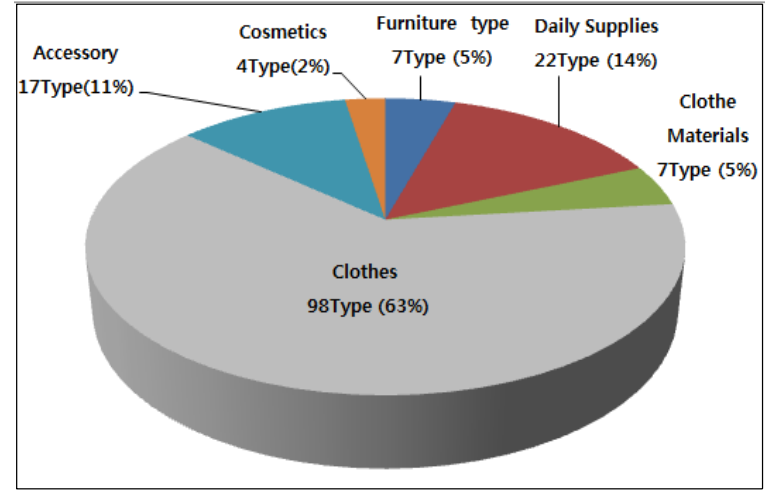

<Fig. 5> A composition graph of Cheongju Han Family list of wedding gifts

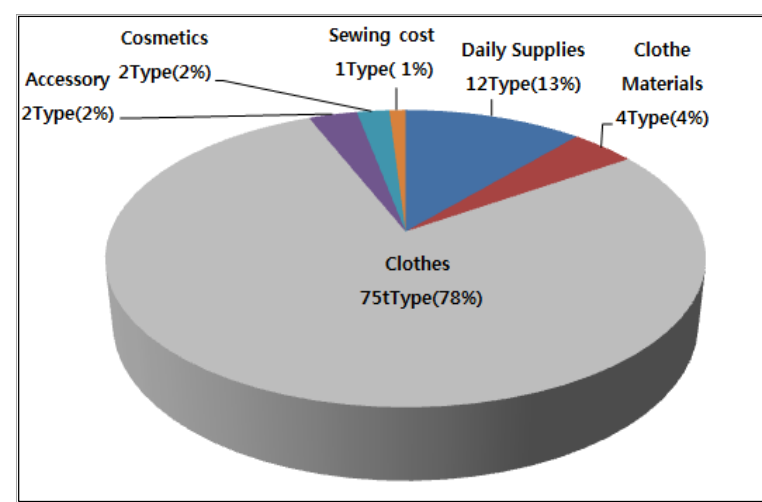

<Fig. 6> A composition graph of Haman Lee Family list of wedding gifts

되어 있다.

의복류 중 치마·저고리 직물의 종류는 대부분 견 직물로 만들어졌다. 저고리 색상은 유록색, 분홍, 진 옥색, 송화색, 자양색, 팥죽색, 남색, 옥색이 있다. 치 마 색상은 옥색, 분홍색, 팥죽색, 밤물색이 있다. 저고 리는 27점이며, 치마는 31점이다. 기존의 구술연구에 서 경상도 지역은 저고리 갯수를 치마보다 더 많이 해주었다는 결과와는 다른 경향을 보이고 있다.

경상도 지역의 가난한 집에서는 혼례식 때 적삼을 입기도 하였는데, 이때 적삼에 사용된 옷감은 흰 방 초, 무명, 모시, 삼베, 안동포 등이었다고 한다(KOCIS, 1986). 본 혼례물목에서 적삼의 옷감으로 사용 된 직물은 도람, 옥당목, 모시, 남저, 안동포, 제포, 대 문포 등이 기록되어 있다. 경상남도 진주·사천지역에 서는 요대를 젖싸개라고 하는데(KOCIS, 1986), 혼례 물목에는 명주로 만들어진 누비요대가 1종이 있다. 혼례물목에는 바지, 누비바지, 겹바지가 기록되어 있
다. 누비바지는 옥당목, 당목, 삼승으로 만들어졌으 며, 겹바지는 당항나, 옥당목, 모시, 양사 등 다양한 직물로 만들어졌다. 단의는 '단속곳'으로 경상도 지역 에서는 '다네'라고도 하며, 속곳 하나만 입을 때는 부 리에 깝댕의[댕기]을 맸다가 용변을 볼 때 풀었다고 한다(KOCIS, 1986). 본 혼례물목에는 명주, 목항나, 모시, 옥당목의 등 견직물, 마직물, 면직물로 직물로 만들었다.

옷감은 필과 통 단위로 한 필에서 많게는 일곱 필 까지 기록되어 있다. 이중 중목이 일곱 필로 수량이 가장 많아, 일상생활에서 활용도가 높은 직물이었을 것으로 사료된다. 의료소재류는 오색 당사와 면사 다 섯 수리가 기록되어 있다.

장신구류는 대발낭자채, 갑사단기[댕기], 은수복잠, 금파잠, 백통잠, 매화잠, 소잠, 족두리, 큰댕기가 기록 되어 있다. 경상도 지역의 민속조사보고서 인터뷰에 서 혼례 앞서 신랑이 도착하기 전에 신부머리에 사용 했다는 낭자채가 본 혼례물목에 기록되어 있음을 확 인할 수 있다.

생활용품류에는 인도[다리미]와 전도[가위]의 기록 이 있다. 경상도의 혼수 풍습에는 다리미와 가위는 친정에서 보내면 못 산다고 해서 시댁에서 마련하여 (Hong et al., 2002) 신부측으로 보낸 것으로 사료된 다. 가구류는 의함, 장롱, 목농, 상자, 머리함, 성적함, 연갑이 기록이 있는 것으로 보아 신랑측에서 마련하 는 경상도 지역의 특징적인 혼수풍습을 확인할 수 있 었다.

1915년 함안 이씨 집안 혼례물목의 품목 종류를 분석하면 〈Table 3〉과 같다. 의복류는 75종이며, 겉옷 은 저고리 13종 15 점, 치마 14 종 27 점이다. 속옷은 적 삼 8종 13점, 겹적삼 3종 4점, 요대 8종 13점, 내의 2종 8점, 겹바지 3종 3점, 핫바지 2종 2점, 바지 1종 1 점, 고의 4종 6점, 단의 2 종 3 점이 기록되어 있다. 옷 감은 9종, 치마 허리감 2 종, 안고름감과 동정대 4종이 기록되어 있다.

저구리로 기록되어 있는 저고리는 13 종 15 점이며, 치마는 14 종 27 점이다. 기존 선행연구에서 저고리 갯 수를 치마보다 많이 해 주는 결과와는 다른 경향을 보이고 있다. 요대는 8종 13점이며, 세올누비, 홋요대, 겹요대 등이 기록되어 있다. 여름에는 모시나 고운 직 물로 만들며, 봄, 가을에는 무명을 겹으로 만들었으 
$<$ Table 2> List of wedding gifts of Cheongju Han Family

\begin{tabular}{|c|c|c|c|c|c|}
\hline \multicolumn{3}{|c|}{ Item } & Types & \multirow{3}{*}{$\begin{array}{c}\begin{array}{c}\text { Item } \\
\text { quantity }\end{array} \\
\\
27\end{array}$} & \multirow{3}{*}{$\begin{array}{c}\text { Amount } \\
\\
27\end{array}$} \\
\hline \multirow{11}{*}{ Clothes } & \multirow{4}{*}{ Outer } & \multirow[t]{2}{*}{ Jeogori } & $\begin{array}{l}\text { Mobondan, Yeongchodan, Suksa, } \\
\text { Myeongju, Gapsa, Sukgosa, Gosa, } \\
\text { Ransa, Gwansa, Mumungwansa, } \\
\text { Okdangmok }\end{array}$ & & \\
\hline & & & $\begin{array}{l}\text { Yurok, Bunhong, Jinok, Songhwa, } \\
\text { Jayang, Patjuk, Namsaek, Oksaek }\end{array}$ & & \\
\hline & & Skirt & $\begin{array}{c}\text { Banju, Okangna, Dorosa, Rausa, } \\
\text { Saenghangna, Dangmok, Ogyangmok, } \\
\text { Mumyeong, Mosi, Munpo, Mapo }\end{array}$ & 24 & 31 \\
\hline & & & Oksaek, Bunhong, Patjuk, Bammul & & \\
\hline & \multirow{6}{*}{$\begin{array}{l}\text { Under } \\
\text {-wear }\end{array}$} & Jeoksam & $\begin{array}{c}\text { Danghangna, Okdangmok, Mosi, Doroma, Jepo, } \\
\text { Daemunpo, Andongpo, Namjeo, Samseung }\end{array}$ & 9 & 11 \\
\hline & & Pants & $\begin{array}{c}\text { Hangna, Yangsa, Okdangmok, Dangmok, } \\
\text { Samseung, Mosi }\end{array}$ & 10 & 10 \\
\hline & & Danui & Myeongju, Okdangmok, Mosi, Mokangna, & 5 & 5 \\
\hline & & Dangoui & Mumyeong, Mosi, Munpo & 3 & 3 \\
\hline & & Naeui & Mumyeong, Mapo & 2 & 2 \\
\hline & & Yodae & Myeongju & 1 & 1 \\
\hline & \multicolumn{2}{|c|}{ Textile } & $\begin{array}{c}\text { Myeongju, Hangna, Dorosa, Sukhangna, Dangmok, } \\
\text { Semok, Ogyangmok, Jungmok, Mosi, Saengmosi, } \\
\text { Baekpo, Nakje, Andongpo, Jepo, Bukpo, Munpo, } \\
\text { Mapo, Samseung }\end{array}$ & 17 & - \\
\hline \multicolumn{3}{|c|}{ Cloth materials } & $\begin{array}{c}\text { Myeonsa, Ihapsa, Samhapsa, Baengnosa, Gaksaek, } \\
\text { Yangsa, Osaek, Dangsa }\end{array}$ & 7 & - \\
\hline \multicolumn{3}{|c|}{ Accessory } & $\begin{array}{l}\text { Daeballangjachae, Gapsadangi, Eunsubokjam, Geumpajam, } \\
\text { Baektongjam, Maehwajam, Jokduri, Keundaenggi, Sojam }\end{array}$ & 17 & - \\
\hline \multicolumn{3}{|c|}{ Cosmetics } & Yeonji, Bun, Soap, Meoritgireum & 4 & - \\
\hline \multicolumn{3}{|c|}{ Daily supplies } & $\begin{array}{c}\text { Jinso, Wolso, Jokjipge, Daeya, Yoganggwa, Indo, Jeondo, } \\
\text { Chimcheok, Golmo, Echim, Jungchim, Jongi, Meok, } \\
\text { Byeoru, etc. }\end{array}$ & 22 & - \\
\hline \multicolumn{3}{|c|}{ Furniture } & $\begin{array}{c}\text { Uiham, Jangnong, Mongnong, Sangja, Meoriham, } \\
\text { Seongjeokham, Yeongap }\end{array}$ & 7 & - \\
\hline \multicolumn{4}{|r|}{ Total } & 155 & - \\
\hline
\end{tabular}

며, 겨울 방한용은 명주, 무명에 솜을 두어 누볐다 (Lee, 1990). 본 혼례물목에서 요대에 사용된 직물은 당목, 면사, 무명으로 만들어졌다. 다른 혼례물목과 달리 한복 제작 시 부속 재료인 당목 치마 허리감, 안
고름감, 동정대 대한 기록이 있는 것이 특징이다. 생 활용품류에 인도와 전도가 기록되어 있어 경상도의 혼수 풍습 중 인도와 전도를 신랑집에서 준비하는 기 존의 구술연구와는 다른 경향을 보이고 있다. 혼례물 
$<$ Table 3> List of wedding gifts of Haman Lee Family

\begin{tabular}{|c|c|c|c|c|c|}
\hline \multicolumn{3}{|c|}{ Item } & Types & \multirow{3}{*}{$\begin{array}{c}\text { Item } \\
\text { quantity } \\
\\
13\end{array}$} & \multirow{3}{*}{$\begin{array}{c}\text { Amount } \\
15\end{array}$} \\
\hline \multirow{12}{*}{ Clothes } & \multirow{4}{*}{ Outer } & \multirow[b]{2}{*}{ Jeogori } & $\begin{array}{l}\text { Mobondan, Ridan, Yeongcho, Toju, } \\
\text { Saengju }\end{array}$ & & \\
\hline & & & $\begin{array}{l}\text { Nyurok, Aengsaek, Chorok, Bora, } \\
\text { Songhwasaek, Yeondusaek, Jinhong, } \\
\text { Geumhaeng, Oksaek, Wollamsaek }\end{array}$ & & \\
\hline & & \multirow[t]{2}{*}{ Skirt } & $\begin{array}{l}\text { Myeongju, Dangmok, Ogyangmok, } \\
\text { Mumyeong, Mosi, Yangsa }\end{array}$ & \multirow[t]{2}{*}{14} & \multirow{2}{*}{27} \\
\hline & & & Oksaek, Jinhong, Bunhong, Banmul & & \\
\hline & \multirow{6}{*}{$\begin{array}{l}\text { Under } \\
\text {-wear }\end{array}$} & Jeoksam & Hangna, Dangmok, Mumyeong, Mosi, Gyechuri & 11 & 11 \\
\hline & & Pants & Hangna, Dangmok, Mumyeong & 6 & 6 \\
\hline & & Danui & Dangmok, Mosi & 2 & 3 \\
\hline & & Goui & Dangmok, Mumyeong, Gyechuri, etc. & 4 & 6 \\
\hline & & Naeui & Mumyeong, Banpo & 2 & 10 \\
\hline & & Yodae & Dangmok, Myeonsa, Mumyeong & 8 & 13 \\
\hline & \multicolumn{2}{|c|}{ Textile } & Myeongju, Dangmok, Semok, Jungmok, Mosi, Gyechuri & 9 & - \\
\hline & \multicolumn{2}{|c|}{ Etc. } & Chima Heorigam, Angoreumgam, Dongjeongdae, etc. & 6 & - \\
\hline \multicolumn{3}{|c|}{ Cloth materials } & Myeonsa, Dangmoksil, Saeksa, Geohwa & 4 & - \\
\hline \multicolumn{3}{|c|}{ Accessory } & Baektong Donggot, Eunjihwan Han Ssang & 2 & - \\
\hline \multicolumn{3}{|c|}{ Cosmetics } & Yeonjimisu, Bunmisu & 2 & - \\
\hline \multicolumn{3}{|c|}{ Daily supplies } & $\begin{array}{l}\text { Mirror, Yogang, Sikgidaejeop, Sujeojip, Jinso, Wolso, } \\
\text { Waeso, Indo, Jeondo, Chimcheok, Jungsechim, etc. }\end{array}$ & 12 & - \\
\hline \multicolumn{3}{|c|}{ Sewing cost } & Chimseonga(20Nyang) & 1 & - \\
\hline \multicolumn{4}{|r|}{ Total } & 96 & - \\
\hline
\end{tabular}

목 마지막 부분에 침선가로 20 냥이 기록되어 있어 신 부측에서도 신랑측으로 침선가를 보낸 것으로 사료 된다.

청주 한씨와 함안 이씨 집안의 혼례물목 품목 종류 와 수량은 많은 차이를 보이고 있다. 함안 이씨 집안 (신부측)의 혼례물목은 가구류에 대한 기록이 없으며, 청주 한씨(신랑측) 집안의 혼례물목은 가구류가 7종 이 기록되어 있다. 이것은 신랑측에서 가구를 마련하 는 경상도 지역의 혼수풍습 때문인 것으로 사료된다. 또한 장신구류 중 유일하게 백동 동곳만 기록되어 있 는 것은 신부측에서 신랑측으로 보낸 혼례물목이기 때문이라고 사료된다.
2. List of wedding gifts of Jinju Jin Yang $\mathrm{Ha}$ Family

〈Fig. 7〉은 1918년 하순봉의 혼례에 사용된 혼례물 목이다. 함양 개평의 하동 정씨(河東 鄭氏) 정순조(鄭 淳兆)의 딸에게 보내어졌으며, 문서의 크기는 331 $\mathrm{cm} \times 21 \mathrm{~cm}$ 이다.

〈Fig. 8〉은 1930년 하순보의 혼례에 사용된 혼례물 목이다. 안동 권씨(安東 權氏) 안경환(安景煥)의 딸에 게 보내어졌으며, 문서의 크기는 $326 \mathrm{~cm} \times 22 \mathrm{~cm}$ 이다 (The Academy of Korea Studies, 2000). 하순봉과 하 순보의 족보에서 나타나는 관계는 하우식(河祐植)과 정철기(鄭菇基) 사이에 태어난 4남 4녀 중 하순봉은 


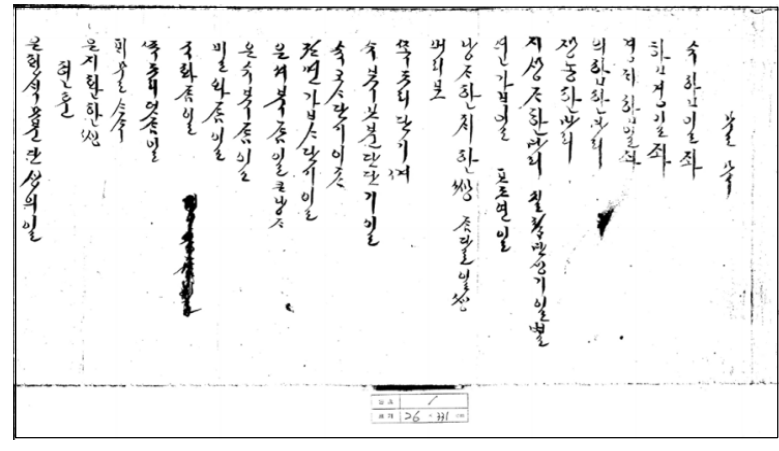

<Fig. 7> A list of wedding gifts of $\mathrm{Ha}$, Soon-bong. From. The Academy of Korea Studies. (2000). p. 921.

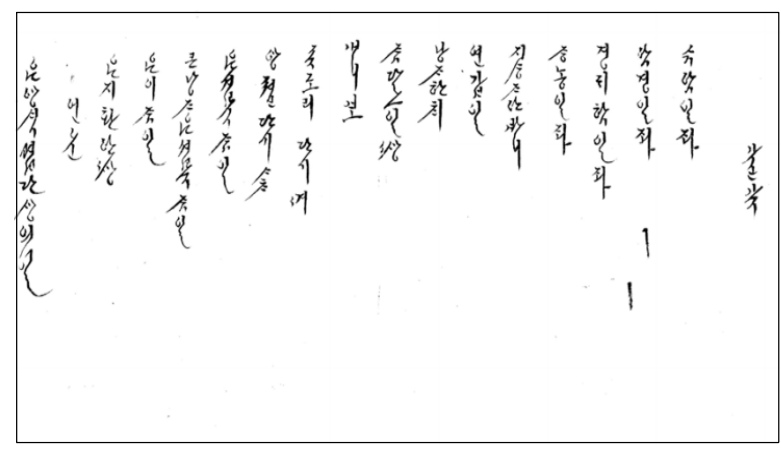

<Fig. 8> A list of wedding gifts of Ha, Soon-bo. From. The Academy of Korea Studies. (2000). p. 929.

장남이고, 하순보는 삼남이다(The Academy of Korea Studies, 2000).

〈Fig. 9〉는 하순봉 혼례물목의 품목 종류와 비중을 분석한 그래프이다. 하순봉 혼례물목의 품목 종류는 총 163 종이다. 의복류가 102종으로 전체 물목에 $63 \%$ 를 차지하며, 생활용품류가 22종(13\%), 장신구류가 16 종 $(10 \%)$, 가구류가 8 종 $(5 \%)$, 의료소재류가 9종 $(5 \%)$, 화장품류가 6 종(4\%)이었다.

〈Fig. 10〉은 하순보 혼례물목의 품목 종류와 비중 을 분석한 그래프이다. 하순보의 혼례물목 품목 종류 는 총 140 종이다. 이중 의복류가 92 종으로 전체 물목 에 $66 \%$ 를 차지하며, 생활용품류가 23 종 $(16 \%)$, 장신 구류가 10 종(7\%), 의료소재류가 5종(4\%), 가구류가 6 종 $(4 \%)$, 화장품류가 4 종 $(3 \%)$ 이었다.

1918년 하순봉 혼례물목의 품목 종류를 분석하면 〈Table 4〉와 같다. '현훈'이라는 제목이 붙여져 있고, 그 이후 의복류가 기록되어 있다. 현훈은 푸른색 옷 감과 붉은색 옷감을 지칭하는 것으로 알려져 있으나 (Jo, 1983), 본 혼례물목에서는 분홍색, 은색, 송화색,

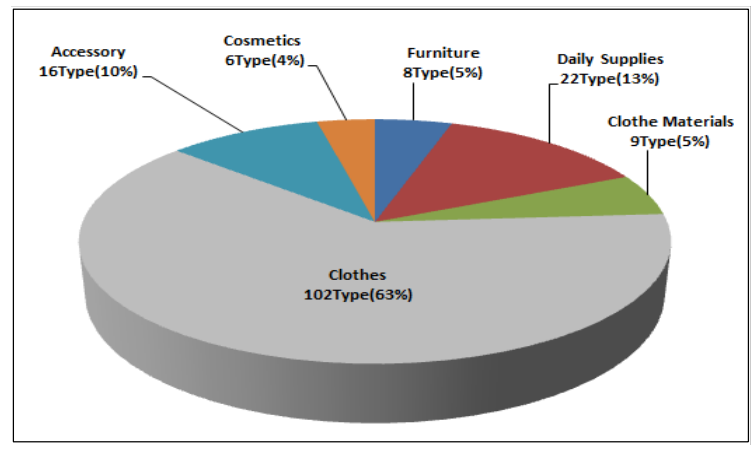

<Fig. 9> A composition graph of $\mathrm{Ha}$, Soon-bong's list of wedding gifts

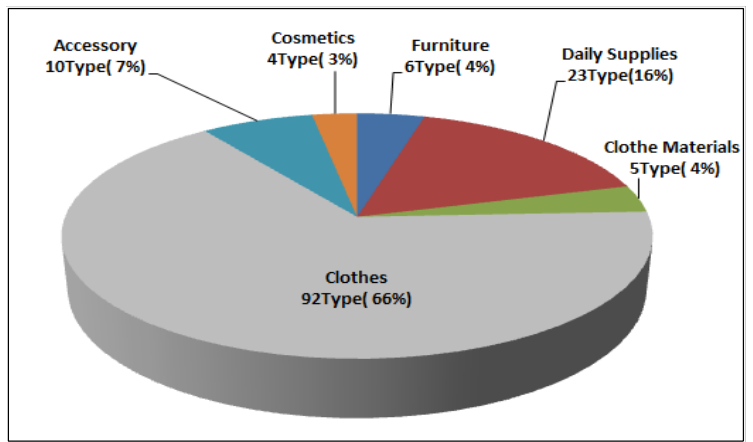

$<$ Fig. 10> A composition graph of Ha, Soon-bo's list of wedding gifts

미색, 유록색, 제색 등 다양한 색상의 치마·저고리가 기록되어 있다.

의복류는 102 종이며, 겉옷은 저고리 16 종 18 점, 겹 저고리 10 종 13 점, 치마 20 종 31 점이다. 속옷은 홋적 삼 15 종 23 점, 요대 5종 12점, 누비요대 1종 1점, 바 지 8종 8점, 핫바지 5종 6점, 겹바지 2종 2점, 고쟁이 6종 6점이다. 내의 2종 10 점, 옷감 12 종이 기록되어 있다.

하순봉 혼례물목의 저고리는 16 종 18 점, 겹저고리 10 종 13 점, 치마 20 종 31 점이다. 이것은 경남지방의 혼례문화 중 치마. 저고리는 수는 짝을 맞추지 않고 보통 치마보다 저고리를 하나 더해주는 풍습(Hong et al., 2002)에서 비롯된 것으로 사료된다. 하의는 옷감 의 소요량이 많아 상대적으로 옷감 소요량이 적은 상 의의 갯수를 많이 제작하여 상-하의의 색상과 직물 을 달리하여 착용했을 것으로 사료된다. 본 혼례물목 에는 요대 5종 12점, 누비요대 1종 1점이 기록되어 있다. 요대는 서양 속옷의 유입으로 현대의 한복 착 용에 있어 사라진 속옷이나, 1918년 혼례물목에 6종, 
$<$ Table 4> List of wedding gifts of Ha, Soon-bong

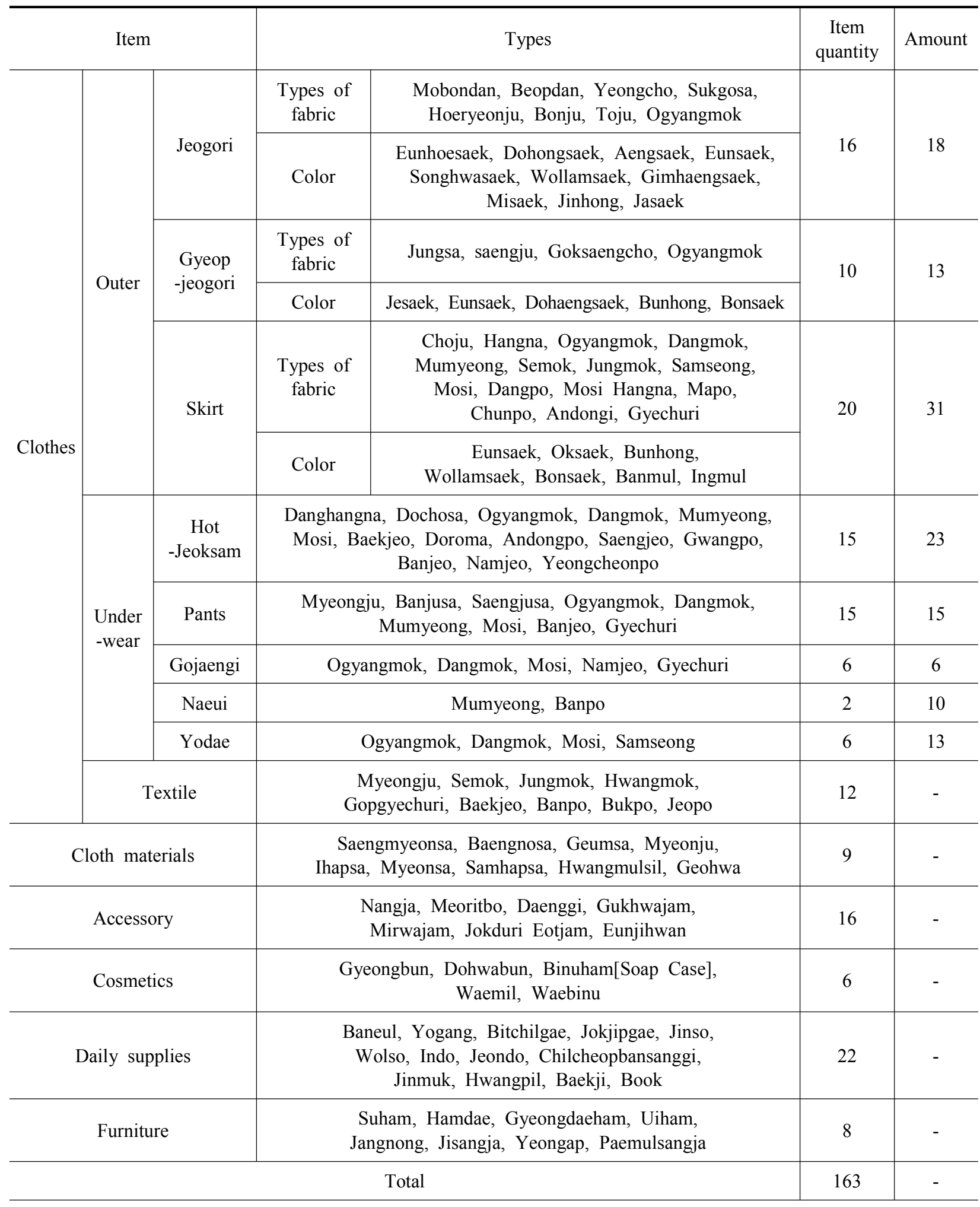

13점이 있어 당시에는 착용하였던 것으로 사료된다.

옷감은 12 종으로 통 단위는 당목과 옥양목이 각각 한통이고, 나머지 옷감은 필 단위로 기록되어 있다.
경상도 지역은 옷감을 신랑측에서 준비하여 신부측 으로 보내면 신부측은 바느질하여 혼수에 필요한 옷 을 마련하는 지역적 특징(Hong et al., 2002)을 하순 
봉의 혼례물목을 통해 확인할 수 있다. 솜은 '닷근'으 로 기록되어 있으며, 신부집에서 이불을 만들 때 사 용되었을 것으로 사료된다.

장신구류 중 단기[댕기]는 경상도 지역의 여름용은 숙고사로 만들었으며, 겨울용 댕기는 법단, 학단, 호 박단으로 만들어 사용했다. 구술에 의하면 비단댕기 는 무거워 미끄러지므로 숙고사를 많이 사용했다 (KOCIS, 1986). 본 혼례물목의 혼례 계절은 알 수 없 으나, 댕기의 소재로 숙고사, 모본단, 갑사가 기록되 어 있어 구술연구 내용과 일치한다.

화장품류는 경분, 도화분, 비노함[비누], 일본 머릿 기름인 왜밀(National Folk Museum of Korea, 2013), 왜비누 등이 있다. 〈Fig. 11〉은 1917년 7월 동화약방 (同和藥房)이 일간지에 게재한 도화분 광고이다. 조선 일품(朝鮮一品)으로 도화분은 정가 금십오전으로 광 고하고 있다(Dong-wha Medicine, 1917). 경상도 지방 의 1918 년도 혼례물목에 도화분이 기록된 것으로 보 아 1917년 전·후반 인기 있는 화장품이었기 때문에 혼례물목에도 포함되었을 것이다. 도화분의 기록은 연대를 추정할 수 없는 혼례물목의 연대를 추정할 수 있을 것이다.

1930년 하순보 혼례물목의 품목 종류를 분석하면 〈Table 5〉와 같다. 의복류는 92종이다. 겉옷은 저고리 18 종 30 점, 겹저고리 8종 8점, 치마 14종 24점이다. 속옷은 홋적삼 14 종 23 점, 요대 2종 5점, 내의 2종 10 점, 바지 1종 1점, 핫바지 4종 4점, 겹바지 2종 2점, 단의 11 종 13 점, 고장의 6 종 6 점이다. 옷감은 10 종이 기록되어 있다.

장남 하순봉 혼례와 삼남 하순보의 혼례 시기는 12 년의 차이가 있지만, 혼례물목의 구성은 유사하였 다. 두 혼례물목에 모두 의복류의 비중이 $63 \%$ 와 $66 \%$ 로 가장 높아 혼례물목에서 의복류가 중요한 품목임 을 알 수 있다. 또한 경남 지역의 혼례에서 특징적으

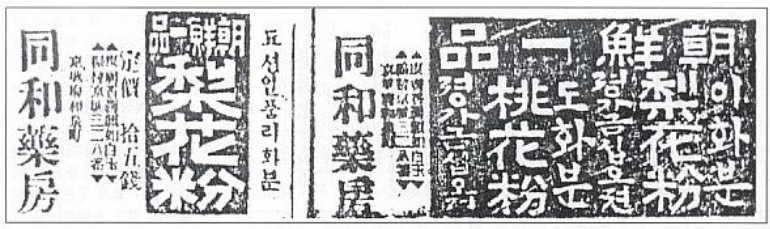

<Fig. 11> Dohwabun Advertising.

From. Dong-wha Medicine. (1917). www.dong-wha.co.kr
로 사용되는 것으로 알려진 향건을 대신하여 착용한 머리보가 하순봉과 하순보의 두 혼례물목에 모두 기 록되어 있었다.

하순보의 혼례물목에 나타난 품목의 종류를 분석 한 결과 〈Table 5〉는 하순봉 혼례물목의 품목 종류를 분석한 결과와 유사하였다. 다만, 장남의 혼례물목이 삼남의 것보다 의복 10 종, 장신구 6 종, 가구류 2 종, 의료소재 4종, 화장품류 2종으로 총 24종이 더 많았 으며, 생활용품류는 삼남의 것이 1종 더 많았다. 조선 시대 후기에 장남 우선에 따른 유교적 이념이 장남과 삼남의 혼례물목에서 약간의 품목수의 차이를 보이 고 있다고 사료된다.

\section{List of wedding gifts of Goseong Jeon Ju Choi}

\section{Family}

경남 고성 학립마을에 고성 전주 최씨 집안은 집성 촌을 이루고 있다. 최은석은 최재호와 함안 조씨 조 점희와의 사이에 출생하였다. 최은석은 1938년인 무 인년 십이월 십일에 김태임(金太壬)과 혼인하였다. 최 영덕은 최은석과 김태임의 사이에 태어난 아들이며, 1976년 평산 신씨 신동선(申東善)과 신식 결혼을 하 였다. 〈Fig. 12〉는 최은석 혼례물목으로 장신구류와 의복류가 기록된 부분이다. 〈Fig. 13〉은 '물목'이라는 제목으로 시작되는 최영덕 혼례물목이다.

〈Fig. 14〉는 최은석 혼례물목의 품목 종류와 비중 을 분석한 그래프이다. 최은석 혼례물목의 품목 종류 는 총 163 종이다. 의복류가 112 종으로 전체 물목에 약 $68.99 \%$ 를 차지하고 있다. 장신구류가 14 종 $(9 \%)$, 생활용품류가 22 종 $(13 \%)$, 가구류가 8 종 $(5 \%)$, 의료소 재류가 6 종 $(4 \%)$, 화장품류가 1 종 $(0.01 \%)$ 이었다.

〈Fig. 15〉는 최영덕 혼례물목의 품목 종류와 비중 을 분석한 그래프이다. 최영덕 혼례물목의 품목 종류 는 총 29 종이다. 의복류가 18 종으로 전체 물목의 $62 \%$ 를 차지하였고, 장신구류가 11 종 $(38 \%)$ 이었다.

1938년 최은석 혼례물목의 품목 종류를 분석하면 〈Table 6)과 같다. 의복류는 112 종이며, 겉옷은 저고 리가 8종 31점, 겹저고리 5종 17점, 치마 18종 40점 이다. 속옷은 홋적삼 4종 14점, 내의 4종 9점, 바지 5 종 5 점, 겹바지 10 종 16 점, 단의 13 종 18 점, 고장의 10 종 14 점이다. 각종 옷감 31 종과 판독이 불가능한의 복류 4종이 기록되어 있다.

의복류 중 저고리 8 종, 겹저고리가 5 종, 치마가 18 
$<$ Table 5> List of wedding gifts of Ha, Soon-bo

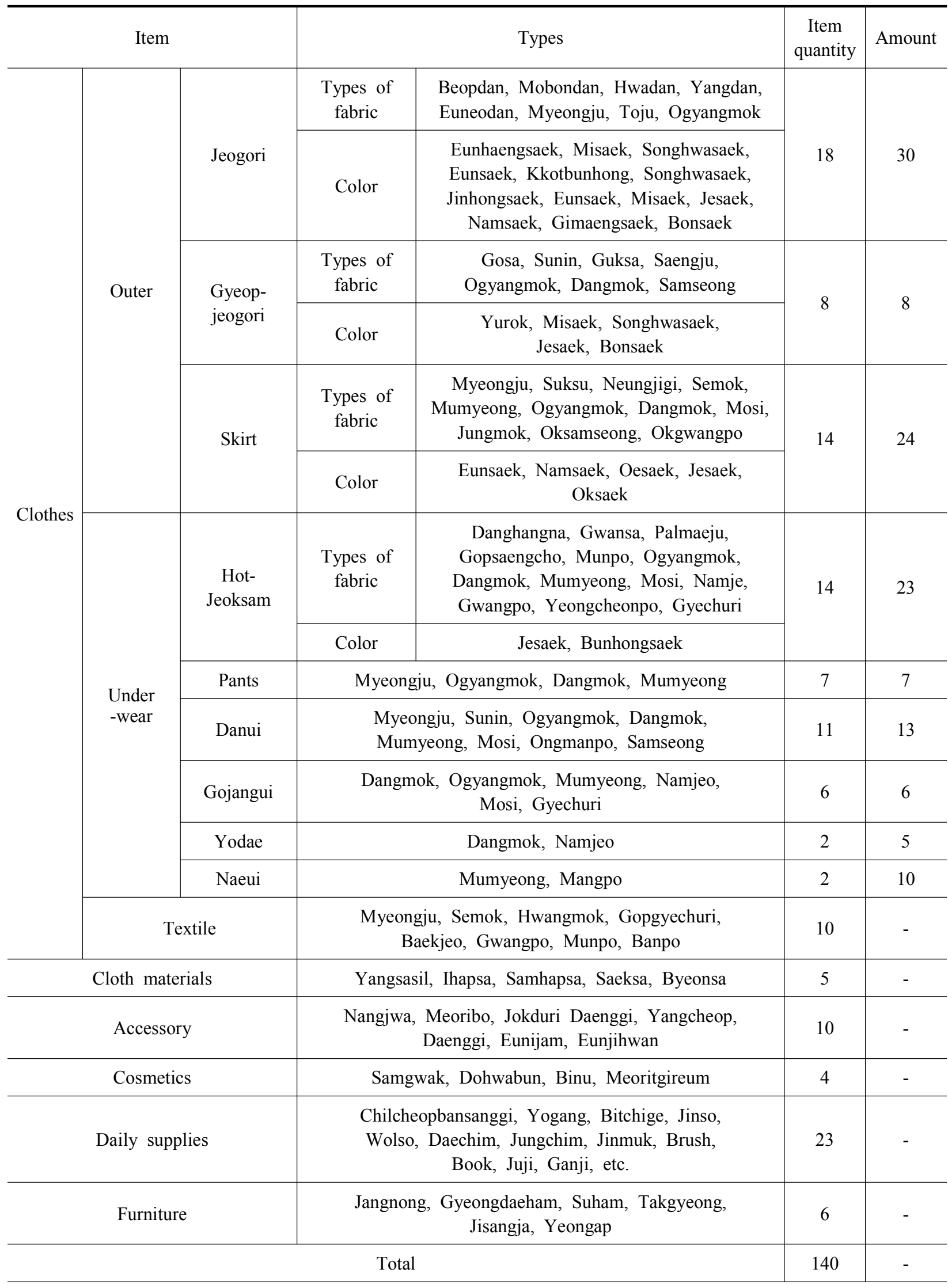


$<$ Table 6> List of wedding gifts of Choi, Eun-suk

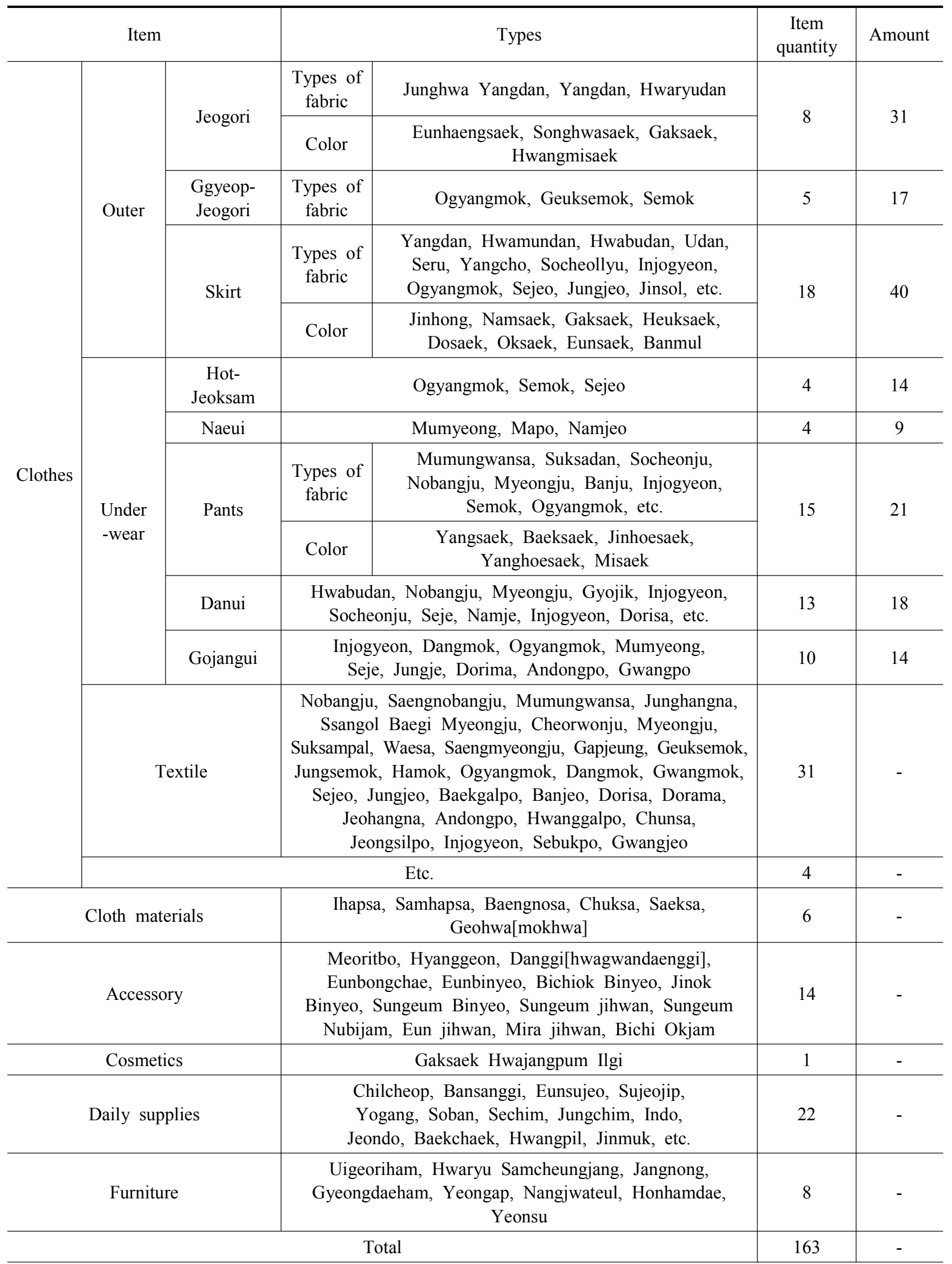




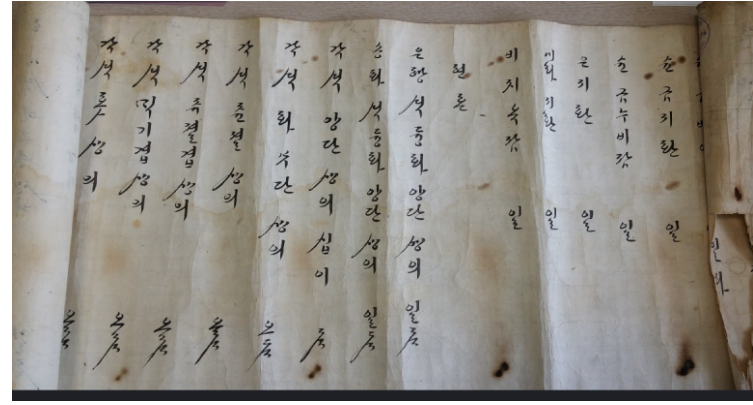

<Fig. 12> A list of wedding gifts of Choi, Eun-suk. (Muncheongak at Gyeongsang National University)

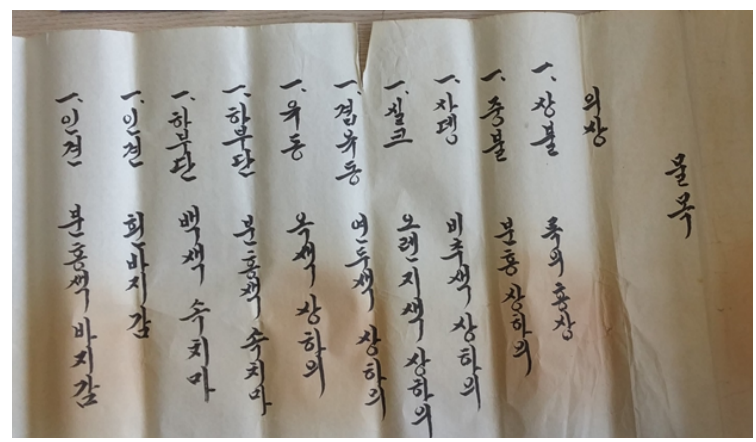

<Fig. 13> A list of wedding gifts of Choi, Eyeong-deok. (Muncheongak at Gyeongsang National University)

종으로 치마의 품목수가 많았으나, 점수를 확인한 결 과, 저고리류가 48점, 치마가 40점으로 저고리가 많 았다. 저고리류의 옷 점수가 많은 것은 하나의 품목 에 다수의 수량이 기록되어 있기 때문이다. 저고리에 사용된 직물은 중화양단, 양단, 화류단이며, 치마에 사용된 직물은 양단, 화문단, 우단, 화부단, 세루, 양 초, 소천류, 인조견, 옥양목 등으로 만들어졌다. 치마 - 저고리의 직물 중 공통적으로 중화 양단과 양단의 기록을 살펴볼 수 있다.

옷감은 31 종이며, 옥양목, 당목, 광목, 세북포, 광저 는 통단위로 기록되어 있다. 노방주, 생노방주, 무문 관사, 중항나, 쌍올 백이 명주, 철원주, 명주, 숙삼팔, 왜사, 생명주, 갑증, 세저, 중저, 백갈포, 반저, 도리사, 도라마, 저항나, 안동포, 황갈포, 춘사, 정실포, 인조 견, 극세목, 중세목, 하목은 필단위로 1 필에서 6 필까 지 다양하게 기록되어 있다. 다른 혼례물목에 비해 다양한 옷감의 종류와 많은 수량이 특징이다.

장신구류는 머릿보, 향건, 화관당기[댕기], 은봉채, 은빈여, 비치옥빈여, 진옥빈여, 순금빈여, 순금지환,

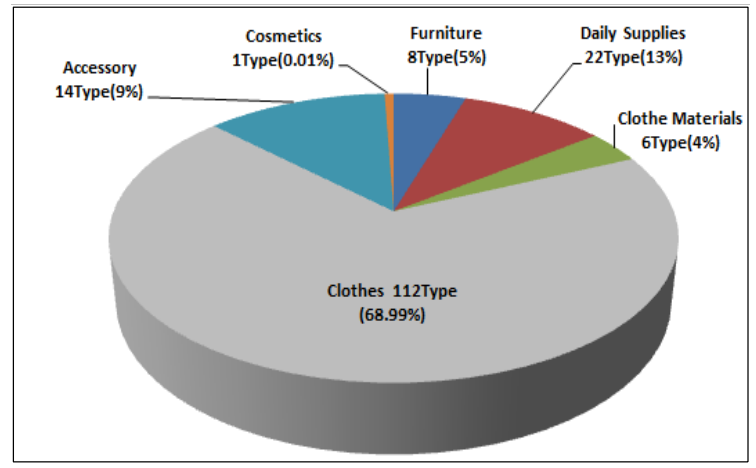

$<$ Fig. 14> A composition graph of Choi, Eun-suk's list of wedding gifts

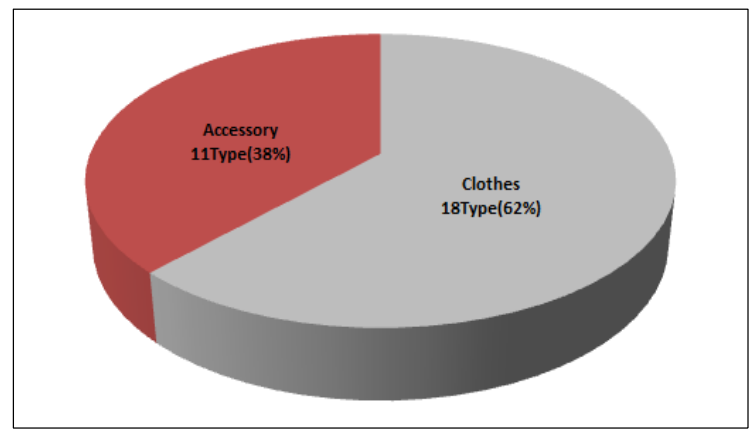

<Fig. 15> A composition graph of

Choi, Eyeong-deok's list of wedding gifts

순금누비잠, 은지환, 미라지환, 비치옥잠 등이 있다. 경남지역 민속자료 보고서에는 순금이 아주 귀하여 혼례는 주로 은비녀가 사용되었다고 조사되었다(KOCIS, 1986). 하지만 최은석 혼례물목에는 다양한 소 재로 만들어진 순금, 옥, 비치옥 등의 비녀가 기록되 어 있어 당시 부유층에서 사용된 비녀의 종류를 파악 할 수 있다. 화장품류는'각색 화장품 일기'라고만 기 록되어 구체적인 화장품의 종류와 수량은 알 수 없었 다.

1938년 최은석 혼례물목과 1915년, 1918년, 1930 년의 혼례물목의 품목 구성은 유사하게 나타나고 있 어, 20세기 초부터 해방이전의 혼례물목은 큰 변화가 없는 것으로 사료된다. 하지만 다른 혼례물목과 달리 품목 종류는 적으나, 한 품목당 수량을 많이 준비하 였다. 최은석의 혼례물목과 1915년 1930년대의 혼 례물목의 차이점은 1930 년대까지 기록에 나타나던 요대가 1938년에는 한건도 기록되어 있지 않다. 저고 리의 길이가 점점 길어지고 치마 어깨허리의 착용과 서양식 속옷의 유입으로 여자의 속옷으로 더 이상 착 
$<$ Table 7> List of wedding gifts of Choi, Eyeong-deok

\begin{tabular}{|c|c|c|c|c|}
\hline \multicolumn{2}{|c|}{ Item } & Types & $\begin{array}{c}\text { Item } \\
\text { quantity }\end{array}$ & Amount \\
\hline \multirow{3}{*}{ Clothes } & Outer & $\begin{array}{l}\text { Sangbul Noguihongsang a suit, } \\
\text { Chadeng Bichusaek a suit, } \\
\text { Silkeu Orange saek a suit, Gyeobyudong a suit }\end{array}$ & 5 & - \\
\hline & Underwear & $\begin{array}{l}\text { Habudan Pink Under Skirt, } \\
\text { Habudan White Under Skirt }\end{array}$ & 2 & - \\
\hline & Textile & $\begin{array}{c}\text { Chunsa, Juhangna, Ingyeon Huinbajigam, Ingyeon Bunhongsaek, } \\
\text { Bajigam, Semokanpil, Ogyangmok, } \\
\text { Samsyeong, Mosi, Saengmosi, Andongpo, Danggalpo }\end{array}$ & 11 & - \\
\hline \multicolumn{2}{|c|}{ Accessory } & $\begin{array}{c}\text { Diamond Ring, Baekgeum Ssangbanji, Gold Necklace, } \\
\text { Gold Eye Ring, Gold Wristband, Gold Square Norigae, } \\
\text { Gold Chilbo Norigae, Oopal A set, Nogak Jae Set, } \\
\text { Pearl Ring, Buroba Watch }\end{array}$ & 11 & - \\
\hline \multicolumn{3}{|r|}{ Total } & 29 & - \\
\hline
\end{tabular}

용되지 않아 혼례물목에서 사라진 것으로 사료된다.

1976년 최영덕 혼례물목의 품목 종류를 분석하면 〈Table 7〉과 같다. 의복류는 상- 하의를 구분하지 않 고 상불 녹의홍상 한 벌, 중불 분홍 상하의, 차뎅 비 추색, 상하의, 실크 오렌지색 상하의, 겹유동 상하의 로 기록되어 있다. 속옷은 하부단 분홍색 속치마, 하 부단 백색 속치마로 기록되어 있고 1938년대의 속옷 의 형태와는 다른 경향을 보이고 있어 속옷의 변천을 살펴볼 수 있었다.

1970년대 경상도 지역의 구술연구에 따르면, 신랑 - 신부 양쪽 모두 혼수 예물로 반지와 시계를 주고받 아 필수적인 혼수예물로 정착되었다(Hong et al., 2002). 최영덕의 혼례물목은 다이아반지[다이아몬드], 진주 반지, 백금반지와 브로바 시계가 기록되어 있어 1970 년대의 혼례예물의 경향을 확인할 수 있었다.

최은석과 최영덕의 부자간 혼례물목은 시대적으로 38 년의 차이가 있다. 그러나 두 혼례물목의 공통점은 의복류가 $60 \%$ 이상을 차지하고 있어 의복의 중요성 은 시대가 바뀌어도 변함이 없는 것으로 사료된다.

1976년 최영덕의 혼례물목은 가구류, 생활용품류, 화장품류, 의료소재류, 침선가가 기록에서 사라졌다. 1938년 혼례물목에 나타나던 장신구류 중 화관댕기, 머리보, 향건, 은봉채 등과 속옷류인 단의, 겹바지, 고 장의, 적삼, 요대와 생활용품류, 화장품류, 가구류, 의 료소재류는 기록에서 사라졌다. 최영덕의 인터뷰에
의하면 혼례물목에는 기록이 없지만, 가구류는 신랑 측에서 마련했다(E.-D. Choi, personal communication, April 6, 2015). 경상도 지방에서 남자가 가구류 를 마련한 지역적 특성은 그대로 유지되었으나, 혼례 물목의 기록에서 사라진 것으로 사료된다.

\section{Conclusion}

본 연구에서 살펴본 20 세기 경남 지역 혼례물목 자료 6 건을 분석한 결과는 다음과 같다.

경남 지방은 다른 지역과 달리 신부가 아닌 신랑측 에서 가구를 준비하는 혼수 풍습이 있다. 신랑측에서 작성한 청주 한씨, 진양 하씨, 전주 최씨 집안의 혼례 물목에는 다양한 가구류 등이 기록된 것을 확인하였 다. 그러나 신부측에서 작성한 함안 이씨 집안의 혼 례물목에는 가구류가 기록되어 있지 않다.

선행연구들의 경남 지방 혼례에서 특징적으로 사 용된다고 알려진 장신구류 중 머리쓰개인 향건과 머 릿보를 혼례물목의 기록을 통해 확인할 수 있었다. 향건은 1938년의 최은석의 혼례물목, 머릿보는 1918 년, 1930년, 1938년도 혼례물목에 나타나고 있다.

혼례와 관련된 경상도 구술연구에서는 경상도 지 역의 경우, 치마-저고리 수를 동일하게 하지 않고 치 마보다 저고리를 하나 더 해주는 혼수 풍습이 있다고 하였다. 그러나 6건의 혼례물목 중 1918년, 1930년, 
1938년 3건의 혼례물목에서 확인할 수 있다. 1976년 의 혼례물목은 의복을 상 - 하의 한 벌로 기록되어 있 으며, 나머지 1915년 2건은 이와 반대의 경향을 나타 고 있다. 또한 1915년 1건의 혼례물목에서 신부측에 서 보낸 혼례물목에 인도와 전도가 포함되어 있어 경 상도 일지라도 집안에 따라 혼례풍습에 차이가 있었 던 것으로 사료된다.

장남의 혼례물목은 삼남의 것보다 의복 10 종, 장신 구 6종, 가구류 2종, 의료소재 4종, 화장품류 2종으로 총 24종이 더 많았다. 조선 후기에 장남 우대에 따른 유교적 이념이 장남과 삼남의 혼례물목 품목과 수량 에서도 차이를 보이고 있다.

부자(父子)간 혼례물목은 38년간의 시대적 차이를 보이고 있어 혼수풍습의 변천을 살펴볼 수 있었다. 전통혼례에 사용되었던 장신구류는 신식혼례가 보편 화 되어 사라진 것으로 사료된다. 또한 1938년에 착 용하던 속옷류인 단의, 고장의, 겹바지는 현대에서는 착용되지 않아 변천을 살펴볼 수 있었다. 1976년 최 영덕 혼례물목은 다양한 반지와 시계가 나타나 1970 년대의 혼례예물의 경향을 확인할 수 있었다.

1915년 1930년대의 혼례물목에 기록된 요대는 저고리의 길이가 점점 길어지고, 치마 어깨 허리의 착용과 서양식 속옷의 유입으로 1940 년 전후로 사라 진 속옷이다. 혼례물목에서 1915년 8종, 1918년 6종, 1930 년 2종의 기록이 있다. 하지만 1938년 최은석의 혼례물목에는 요대가 기록되어 있지 않아 해방 이전 속옷 착용의 변화를 살펴볼 수 있었다.

혼례물목 품목 구성의 비중을 살펴보면, 의복류가 $62 \sim 79 \%$ 로 가장 중요한 품목임을 알 수 있다. 두 번 째로 비중이 높은 것은 5 건의 혼례물목 중 생활용품 류로 10 22\%를 차지하였다. 혼례연도가 1976년인 최영덕의 혼례물목에는 기록되어 있지 않다. 한편, 장 신구류는 1915년, 1918년, 1930년, 1938년의 혼례물 목에서는 3 12\% 차지했으나, 1976년 혼례물목에서 $38 \%$ 로 비중이 높아져 시대에 따른 변화를 확인할 수 있다. 그 밖에 의류소재류는 4 5\%, 가구류는 4 $5 \%$, 화장품류는 $0.01 \% \sim 4 \%$ 를 차지하였다.

본 연구에서 경남 지역 혼례물목의 품목 종류와 비 중의 분석을 통해 기존의 구술연구를 뒷받침하는 문 헌적 근거를 찾고, 경남지역의 혼례문화와 특성을 고 찰하였다. 또한 혼례물목에 기록된 의복류, 장신구류,
가구류, 생활용품류, 화장품류, 의료소재류, 침선가는 당시의 혼례문화와 생활사를 고증-재현하는 학술적 근거 자료가 될 것이다.

\section{References}

Dong-wha Medicine. (1917, July). Dong-wha Media Center. Retrieved January 10, 2017, from https:// www.dong-wha.co.kr/mediaCenter/adGallery/list paper.asp?s_code $=$ B27\&s_year $=$

Hong, N. Y., Lee, E. J., \& Park, S. H. (2002). A study on the changes of the Korean wedding culture in 20th century: Focused on Seoul and Kyungsangdo. Family and Environment Research, 40(11), 141-156.

Jeong, B.-N. (2000). A study of folklore on the traditional wedding of the West Gyeong Nam district: Focused on 1920s 1950s. The Research Journal of the Costume Culture, 8(6), 871-886.

Jo，Y. J. (1983)。家庭罆鑑 [Gajeongbogam]. Seoul: Ilsinseojeokgongsa.

Kim, J. N. (2011). A study on folk custom concerning the traditional wedding ceremony based on old documentary, wedding-catalogs of goods. The Review of Korean Cultural Studies, 38, 361389.

Kim, J. T. (1982). On nuptial presenting in traditional wedding. Journal of the Women's Problems Research Institute, 11, 17-29.

Korean Culture and Information Service. (1972). 韓國 民俗綜合調查報告書: 慶向南道編 [Korean folkore comprehensive investigation report: Gyeongsangnam-do], Seoul: National Research Institute of Cultural Heritage.

Korean Culture and Information Service. (1986). 韓國 民俗綜合調查報告書: 衣生活編 [Korean folkore comprehensive investigation report: Cloth], Seoul: National Research Institute of Cultural Heritage.

Lee, C. W. (1990). A study on everyday wear of Korean common woman with folklore. Family and Environment Research, 28(4), 15-30. 
National Folk Museum of Korea. (2013). Lee, Seukhee's life story, a hundred year journey of a woman through traditional to modernity. Seoul: National Folk Museum of Korea.

The Academy of Korea Studies. (2000). 古文書集成 (Vol. 47) [Gomunseo-Jipseong]. Seoul: Jangseogak.

The Digital Library of Nammyong Study. (2011, October 4). 경상대학교 도서관, '고문헌 기증 위탁식 및 고서화 전시회' [Gyeongsang National University library donation of ancient documents, consignment ceremony and antiquity exhibition].
Retrieved January 30, 2017, from http://nmh. gnu.ac.kr/jsp/bbs/notic_view.jsp?idx $=83 \& \mathrm{pg}=10 \&$ name $=\% \mathrm{EA} \% \mathrm{~B} 4 \% 80 \% \mathrm{~EB} \% \mathrm{~A} 6 \% \mathrm{AC} \% \mathrm{EC} \% 9 \mathrm{E} \% 9$ $0 \&$ flag $=\mathrm{B}$

The Digital Library of Nammyong Study. (2013, May 14). 지극한 효심에 문학성도 뛰어난 장편 한글 제문발견 [Extremely devoted to one's parents and discovery of recognize literary property full-length Hangul letters]. Retrieved January 30, 2017, from http://nmh.gnu.ac.kr/jsp/ bbs/notic_view.jsp?idx $=110 \& p g=9 \&$ name $=\% \mathrm{EA}$ $\% \mathrm{~B} 4 \% 80 \% \mathrm{~EB} \% \mathrm{~A} 6 \% \mathrm{AC} \% \mathrm{EC} \% 9 \mathrm{E} \% 90 \&$ flag=B 